\title{
Kualitas Layanan dan Nilai yang Dipersepsikan terhadap Niat Pembelian Pengguna Jasa MRT dengan Kepuasan Pelanggan Sebagai Mediasi
}

\author{
Vony Riyanto dan Hetty Karunia Tunjungsari \\ Program Studi Manajemen, Fakultas Ekonomi dan Bisnis \\ Universitas Tarumanagara \\ Email: vony28riyanto@gmail.com
}

\begin{abstract}
Success of public transport service marketers is dependent on how they satisfy their customers by delivering value through quality services. To understand this phenomenon, this study aims to investigate the effect of service quality on purchase intention with perceived value and customer satisfaction as mediated variable in Jakarta Mass Rapid transit (MRT) system. A convenience sampling technique was used to collect the data by distributing the questionnaires to the 200 passengers at various MRT stations, where from 200 questionnaires obtained 151 respondents who fulfill the criteria. Partial least squares method of structural equation modelling (PLS-SEM) was used to analyse the collected data and test the hypotheses. The results of this study indicate that service quality can positively influense customer satisfaction, service quality can positively influence customers purchase intention, , perceived value positively influence customer satisfaction, perceived value can't positively influence purchase intention, customer satisfaction can positively influence purchase intention, customer satisfaction can't mediated positively the relationship between service quality and purchase intention, and Customer satisfaction can't mediated positively the relationship between perceived value and purchase intention.
\end{abstract}

Keywords: Service Quality, Perceived Value, Customer Satisfaction, Purchase Intention

\begin{abstract}
Abstrak: Keberhasilan pemasar jasa transportasi umum bergantung kepada bagaimana mereka memuaskan pelanggan dengan memberikan nilai melalui kualitas layanan untuk mencapai niat pembelian pelanggan. Untuk memahami fenomena ini, penelitian ini bertujuan untuk menyelidiki pengaruh kualitas pelayanan terhadap niat pembelian dengan variabel mediasi nilai yang dipersepsikan dan kepuasan pelanggan dalam sistem Mass Rapid Transit Jakarta. Teknik convenience sampling digunakan pada penelitian untuk mengumpulkan data dengan mendistribusikan kuesioner kepada 200 penumpang di berbagai stasiun MRT, di mana dari 200 kuesioner diperoleh 151 responden yang memenuhi kriteria. Metode partial least square dari pemodelan persamaan structural digunakan untuk menganalisis data yang dikumpulkan dan menguji hipotesis. Hasil penelitian ini menunjukkan bahwa kualitas layanan dapat mempengaruhi kepuasan pelanggan secara positif, kualitas layanan dapat mempengaruhi niat pembelian secara positif, kualitas layanan dapat mempengaruhi nilai yang dipersepsikan secara positif, nilai yang dipersepsikan dapat mempengaruhi kepuasan pelanggan secara positif, nilai yang dipersepsikan tidak dapat mempengaruhi niat pembelian secara positif, kepuasan pelanggan dapat mempengaruhi niat pembelian secara positif, kepuasan pelanggan tidak dapat memediasi hubungan antara kualitas layanan dan niat pembelian, serta nilai yang dipersepsikan dapat memediasi hubungan antara kualitas layanan dan kepuasan pelanggan.
\end{abstract}

Kata kunci: Kualitas layanan, nilai yang dipersepsikan, kepuasan pelanggan, niat pembelian 


\section{LATAR BELAKANG}

Kota Jakarta sebagai pusat perekonomian dan pemerintahan. Status Jakarta sebagai salah satu kota dengan tingkat kemacetan yang tinggi bukan lagi rahasia umum, termasuk bagi dunia. Kemacetan itu disebabkan diantaranya oleh tingginya pertumbuhan penduduk di Jakarta ,ketidak seimbangan antara pertumbuhan jalan dengan pertumbuhan kendaraan yang terus meningkat, penggunaan sejumlah ruas jalan yang dijadikan lahan parkir, dan proses pembangunan infrastruktur di Jakarta. Fasilitas dan kualitas layanan transportasi umum yang tidak memadai menjadi alasan masyarakat lebih memilih menggunakan kendaraan pribadi. Selain itu minimnya kesadaran budaya menggunakan transportasi umum bagi sebagian besar masyarakat juga merupakan sebuah penyebab kemacetan dijakarta sulit diurai.

Kurangnya kenyamanan masyarakat pengguna angkutan umum di kota jakarta, semakin memperkuat persepsi masyarakat untuk lebih memilih menggunakan kendaraan pribadi. Tidak heran lagi, Jakarta semakin macet dengan banyaknya kendaraan pribadi yang berkeliaran di jalanan. Melihat beberapa persoalan ini, Jakarta telah melakukan pembenahan sistem transportasi publik dalam kotanya. Jakarta membutuhkan transportasi yang bisa mengakomodasi mobilitas penduduk dengan cepat tanpa harus membebani lalu lintas. Hingga kemudian terobosan baru diperkenalkan, yaitu Mass Rapid Transport atau MRT.

Keberadaan MRT ditunjuk untuk menjadi solusi atas persoalan transportasi umum di Jakarta. Transportasi yang dapat memberikan nilai dan persepsi positif dari masyarakat serta dapat memfasilitasi masyarakat Jakarta yang melakukan perjalanan tanpa terjebak kemacetan lalu lintas. Keberhasilan sistem transportasi umum tergantung pada jumlah pelanggan yang dapat diangkut dan dipertahankan. Untuk alasan ini, peningkatan kualitas dan efisiensi layanan menjadi masalah yang paling penting karena diketahui bahwa peningkatan tingkat kualitas layanan mengarah pada kepuasan pelanggan yang lebih tinggi dan peningkatan penggunaan sistem

\section{KAJIAN TEORI}

Penelitian ini mengacu kepada theory of planned behavior. Menurut Azjen (1991) untuk melihat perilaku individu dapat dilakukan dengan melakukan banyak pendekatan dari banyak tingkat dari faktor psikologis hingga faktor sosial. Konsep yang mengacu pada disposisi perilaku seperti sikap sosial dan sifat kepribadian memiliki peran penting dalam upaya untuk memprediksi dan menjelaskan perilaku manusia. Faktor utama dalam theory of planned behavior ini adalah niat individu untuk melakukan perilaku. Niat diasumsikan sebagai faktor motivasi yang mempengaruhi perilaku tertentu. Niat adalah indikasi tentang seberapa keras orang mau mencoba dan seberapa banyak upaya yang mereka rencanakan untuk melakukan perilaku tersebut. Hal ini dapat disimpulkan bahwa semakin kuat niat untuk terlibat dalam melakukan perilaku makan semakin besar pula kemungkinan kinerjanya. Keterkaitan teori diatas terhadap variabel penelitian ini adalah kualitas layanan, masyarakat pada umumnya cenderung lebih senang menggunakan produk dengan kualitas layanan yang baik. Kemudian nilai yang dipersepsikan pelanggan ini merupakan hal penting karena penilaian kualitas layanan terhadap suatu produk bergantung kepada publik sehingga baik dan buruknya suatu layanan akan berpengaruh kepada niat pembelian. Ketika pelanggan merasa puas akan kualitas layanan yang diberikan maka kemungkinan ia untuk kembali membeli sebuah produk akan lebih besar.

\section{Definisi Konseptual Variabel}

Kualitas layanan adalah aktivitas yang dilakukan oleh perusahaan untuk menyajikan keunggulan dalam penyampaian layanannya dengan tujuan memenuhi dan mempermudah aktivitas transaksi pelanggan sehingga pelanggan dapat merasa aman, nyaman dan puas saat 
menggunakan layanan jasa yang sediakan sesuai dengan apa yang mereka harapkan. Semakin baik kualitas layanan yang diberikan semakin tinggi pula kepuasan yang dirasakan konsumen terhadap produk atau jasa. (Bitner dan Hubbert, 1994., Juran, 1988., Zeithaml, 1988., Weinstein, 1998., Ueltschy dan Krampf, 2001., Parasumanan et al, 1985).I

Nilai yang dipersepsikan merupakan nilai keseluruhan dari pelanggan terhadap layanan yang mereka terima lalu selisih penilaian dari pelanggan terhadap biaya yang mereka keluarkan dengan layanan yang mereka terima. (Rasoolimanesh et al, 2016., Bishop, 1984., Zeithaml, 1988., Lovelock, 2000., Woodruff, 1997).

Kepuasan pelanggan adalah kegiatan memenuhi kebutuhan dan keinginan pelanggan, dengan terpenuhnya kebutuhan dan keinginan tersebut muncul perasaan senang atau kecewa dari pelanggan tentang perbandingan kinerja dirasakan dengan yang diharapkan. Hampir semua perusahaan layanan berusahan untuk mencapai kepuasan pelanggan karena dapat memberikan efek yang sangat besar bagi perusahaan itu sendiri seperti kepercayaan dan loyalitas pelanggan. (Holbrook, 1994., Johnson dan Fornell, 1991., Oliver, 1999., Kotler and Keller, 2009., McDougall dan Levesque, 2000., Hu et al, 2009).

Niat pembelian adalah perilaku konsumen yang menunjukkan adanya niat pembelian terhadap sebuah produk atau jasa di masa depan atau terdapat perasaan bahwa konsumen akan membeli sebuah produk atau jasa pada saat ini juga. (Zeithaml, 1996., Doods et al, 1991., Agarwal dan Teas, 2001., Bitner, 1990).

Kaitan antara Kualitas layanan Terhadap Kepuasan Pelanggan. Dalam penelitian Chongsanguan et al (2017), menyatakan bahwa adanya kaitan yang signifikan positif antara kualitas layanan terhadap kepuasan pelanggan. Dalam penelitian yang dilakukan Hussain et al (2015) penelitian ini menyatakan ketika pelanggan menerima kualitas layanan yang baik mereka akan merasa senang.

Kaitan antara Kualitas Layanan Terhadap Niat Pembelian. Penelitian yang dilakukan Mugion et al (2018) menyimpulkan bahwa kualitas layanan transportasi umum memiliki pengaruh kepada niat pembelian. Berdasarkan penelitian Chongsanguan et al (2017), terdapat keterkaitan yang siginifikan positif antara kualitas layanan terhadap niat pembelian.

Kaitan antara Nilai yang Dipersepsikan Terhadap Kepuasan Pelanggan. Menurut Hsu et al (2012). Nilai yang dipersepsikan dapat mempengaruhi kepuasan pelanggan. Menurut Menurut Kuo et al (2009) mengungkapkan bahwa semakin tinggi nilai yang dipersepsikan dapat menyebabkan kepuasan pelanggan yang lebih tinggi juga.

Kaitan antara Nilai yang Dipersepsikan Terhadap Niat Pembelian. Menurut Ponte et al (2015). Nilai yang dipersepsikan secara positif mempengaruhi niat pembelian. Penelitian ini mengemukakan bahwa nilai yang dipersepsikan merupakan faktor utama dari pembelian online yang berarti semakin besar nilai yang dipersepsikan oleh konsumen semakin besar kemungkinan mereka memiliki niat berbelanja dalam situs web. Menurut penelitian yang dilakukan Chongsanguan et al (2017). Nilai yang dipersepsikan konsumen mempengaruhi niat pembelian.

Kaitan antara Kepuasan Pelanggan Terhadap Niat Pembelian. Menurut Hsu et al (2012). Kepuasan pelanggan mempengaruhi niat pembelian. Penelitian ini menjelaskan bahwa kepuasan mempengaruhi niat pengguna untuk membeli, tingkat kepuasan yang tinggi meningkatkan keinginan untuk terus menggunakan. Oleh karena itu pemasar harus berusaha untuk menekankan efek kesenangan dan hiburan dari layanan mereka untuk meningkatkan kepuasan pengguna dengan demikian akan meingkatkan niat mereka untuk membeli. 
Kaitan antara Kualitas Layanan, Kepuasan Pelanggan Terhadap Niat Pembelian. Menurut penelitian yang dilakukan oleh Bai et al (2008). Kualitas web mempengaruhi niat pembelian melalui kepuasan pengguna dengan fungsionalitas situs web dan fitur kegunaan. Dengan kata lain kepuasan pelanggan memediasi kualitas web terhadap niat pembelian. Menurut penelitian yang dilakukan Mirza (2017) kualitas layanan memiliki keterkaitan terhadap kepuasan pelanggan dan niat pembelian begitu pula kepuasan pelanggan terhadap niat pembelian

Kaitan antara Nilai yang Dipersepsikan, kepuasan pelanggan Terhadap Kepuasan Pelanggan. Menurut Ponte Et al (2015) nilai yang dipersepsikan mempengaruhi niat pembelian pelanggan dan menurut Hapsari (2016) nilai yang dipersepsikan juga memiliki pengaruh yang positif terhadap kepuasan pelanggan.

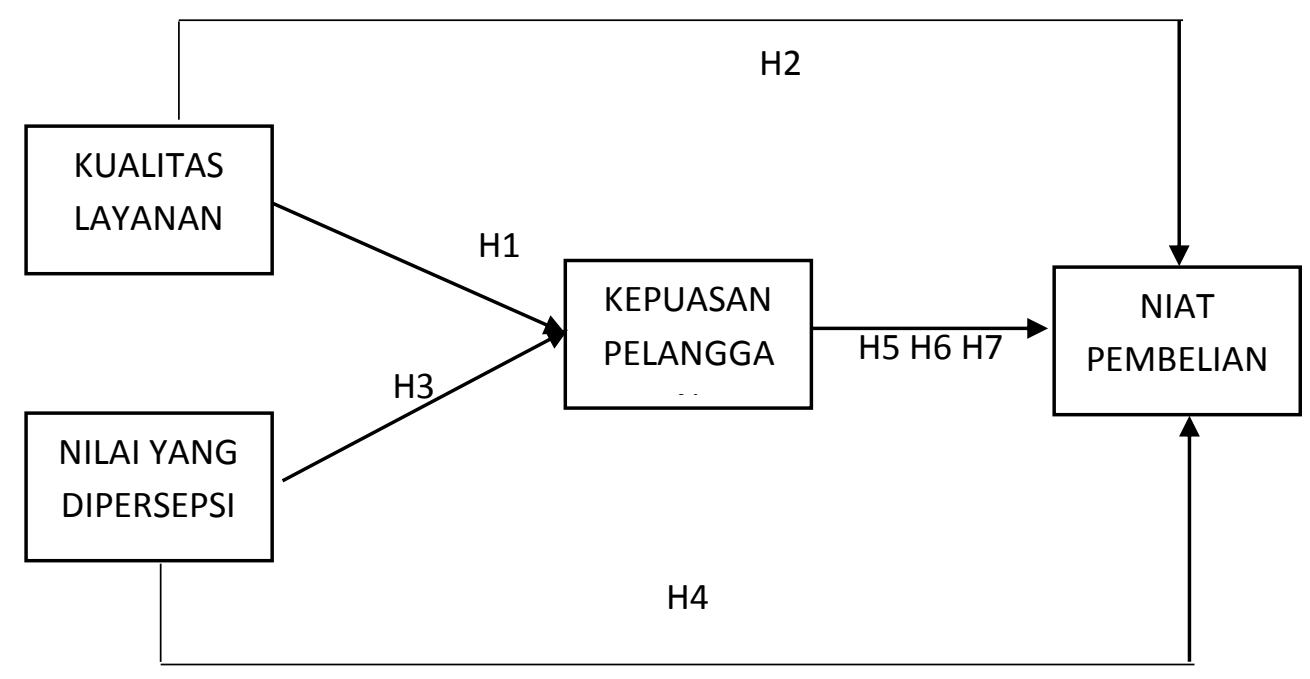

Gambar 1. Model Penelitian

Dari kajian teori, kerangka berpikir, dan model penelitian di atas, dapat diperoleh hipotesis penelitian sebagai berikut:

H1: Kualitas layanan (Service Quality) dapat mempengaruhi secara positif kepuasan pelanggan (Customer Satisfaction) jasa MRT Jakarta

H2: Kualitas layanan (Service Quality) dapat mempengaruhi secara positif niat pembelian (Purchase Intention) pengguna jasa MRT Jakarta.

H3: Nilai yang dipersepsikan (Perceived Value) dapat mempengaruhi secara positif kepuasan pelanggan (Customer Satisfaction) jasa MRT Jakarta

H4: Nilai yang dipersepsikan (Perceived Value) dapat mempengaruhi secara positif niat pembelian (Purchase Intention) pengguna jasa MRT Jakarta.

H5: Kepuasan pelanggan (Customer Satisfaction) dapat mempengaruhi secara positif niat pembelian (Purchase Intention) pengguna jasa MRT Jakarta.

H6 : Kepuasan Pelanggan (Customer Satisfaction) dapat memediasi pengaruh Kualitas Layanan (Service Quality) terhadap Niat Pembelian (Purchase Intention) pengguna jasa MRT Jakarta.

H7 : Kepuasan Pelanggan (Customer Satisfaction) dapat memediasi pengaruh Nilai yang dipersepsikan (Perceived Value) terhadap Niat Pembelian (Purchase Intention) pengguna jasa MRT Jakarta. 


\section{METODOLOGI}

Dalam penelitian ini penulis menggunakan desain penelitian deskriptif dengan crosssectional design. Menurut Aritonang (2007:84). Pada penelitian deskriptif tidak ada variabel yang dimanipulasi, jadi data pada penelitian deskriptif bersifat given, sudah tertentu, sudah ada sebelum penelitian dilakukan, dan bukan data yang diciptakan melalui variabel perlakuan tententu. Penelitian cross-sectional design melakukan penelitian pada satu waktu dan hanya sekali yang bertujuan untuk menguji secara empiris hubungan antar variabel. Dengan metode kuantitatif dan pengumpulan data menggunakan kuesioner yang menggunakan skala likert 16.

Populasi yang digunakan untuk penelitian ini adalah seluruh pengguna MRT Jakarta Menurut Wijaya (2009) pengambilan sampel yang efektif berkisar 150 - 500 sampel. Maka pada penelitian ini digunakan sampel sebanyak 200 sampel. Peneliti menggunakan sampel lebih banyak dari jumlah sampel minimum karena apabila terdapat jawaban kuesioner yang tidak valid, maka responden yang didapat tidak berada dibawah jumlah sampel minimum.

Pengumpulan data dilakukan menggunakan kuesioner dengan skor berupa skala likert. Data dianalisis menggunakan PLS-SEM dimana data diolah dengan program software SmartPLS 3. Pengolahan data yang pertama dilakukan pada outer model untuk menguji validitas dan reliabilitas. Uji validitas dilihat dari nilai Average Variance Extracted $>0,5$ (Hair et al, 2011) dan nilai loading factor > 0,7 (Henseler et al., 2009) maka masih dianggap cukup. Pengolahan data selanjutnya yaitu uji reliabilitas dilihat dari besarnya nilai pada cronbach alpha dan composite reliability harus diatas 0,6 suatu data yang digunakan dapat dinyatakan memiliki reliabilitas.

Pengolahan data yang kedua, yaitu dilakukan pada inner model untuk menguji hipotesis yang telah dihasilkan. Pengujian konstruk penelitian yang pertama dilakukan dengan melihat nilai $\mathrm{R}$-square $\left(\mathrm{R}^{2}\right)$ dengan kriteria 0,67 yang berarti bersifat substansial, 0,33 yang berarti bersifat moderat, dan 0,19 yang berarti bersifat lemah (Henseler et al, 2009). Nilai dari effect size $\left(\mathrm{f}^{2}\right)$ dinyatakan sebesar 0,$02 ; 0,15$ dan 0,35 dengan masing-masing variabel yang menandakan kecil, sedang, dan besar (Henseler et al., 2009). Nilai dari Predictive Relevance $\left(\mathrm{Q}^{2}\right)$ yang dapat dilihat melalui blindfolding yaitu $>0$ adalah berupa 0,02, 0,15, 0,35 untuk relevansi prediktif yang lemah, sedang, kuat. Selanjutnya pengujian melalui mediasi yaitu tstatistics $>1,96 ; \alpha=5 \%$, untuk mengetahui penggunaan full mediation atau partial mediation (MacKinnon, Fairchild, \& Fritz, 2007). Pengujian hipotesis menggunakan t-statistics dalam penelitian ini lebih kecil daripada 1,96 (t-value $=<1,96)$,

Variabel dan jumlah pernyataan yang digunakan dan yang akan diolah datanya dalam penelitian ini, tersaji dalam tabel 1 berikut ini:

Tabel 1. Konstruk Penelitian

\begin{tabular}{|l|l|c|}
\hline No & \multicolumn{1}{|c|}{ Variabel } & Pernyataan \\
\hline 1 & Kualitas Layanan & 22 \\
\hline 2 & Nilai yang Dipersepsikan & 5 \\
\hline 3 & Kepuasan Pelanggan & 4 \\
\hline 4 & Niat Pembelian & 4 \\
\hline
\end{tabular}

Sumber: Skripsi Vony Riyanto (2019) 


\section{Hasil Uji Statistik}

\section{Uji Validitas}

Pada hasil uji validitas telah didapatkan angka pada setiap variabel $>0,7$ pada nilai loading factor kecuali pada variabel kebijakan harga,kesadaran, kepercayaan pengecer, dan loyalitas. Nilai Average Variance Extracted (AVE) yaitu > 0,5 maka semua variabel yang digunakan sudah valid.

\section{Uji Reliabilitas}

Pada hasil reliabilitas, maka berdasarkan hasil yang telah diolah oleh program SmartPLS 3, dinyatakan bahwa angka pada nilai Cronbach's Alpha dan Composite Reliability yaitu > 0,6 maka variabel pada penelitian ini sudah reliabel.

\section{Pengujian Konstruk Penelitian}

Nilai R-square $\left(\mathrm{R}^{2}\right)$ yang dihasilkan pada variabel kepuasan pelanggan memiliki nilai 0,642 yang berarti sebesar $64,2 \%$ (bersifat moderat). Pada variabel niat pembeluan memiliki nilai 0,622 yang berarti sebesar $62,2 \%$ (bersifat moderat). Pada hasil nilai effect size ( $\mathrm{f}^{2}$ ) dijelaskan variabel kualitas layanan memiliki pengaruh terhadap nilai yang dipersepsikan sebesar 1,291 (tergolong besar). Kualitas layanan memiliki pengaruh terhadap kepuasan pelanggan sebesar 0,396 (tergolong besar). Kualitas layanan memiliki pengaruh terhadap niat pembelian sebesar 0,212 (tergolong sedang). Variabel nilai yang dipersepsikan memiliki pengaruh terhadap kepuasan pelanggan sebessar 0,106 (tergolong kecil). Nilai yang dipersepsikan memiliki pengaruh terhadap niat pembelian sebesar 0,012 (tergolong tidak memiliki efek < 0,02). Variabel kepuasan pelanggan memiliki pengaruh terhadap niat pembelian sebesar 0,057 (tergolong kecil). Berdasarkan nilai predictive relevance $\left(\mathrm{Q}^{2}\right)$ dijelaskan bahwa nilai variabel kepuasan pelanggan sebesar 0,449 (relevansi prediktif kuat). Kemudian, nilai dari variabel niat pembelian sebesar 0,387 (relevansi prediktif kuat).

Tabel 2. Hasil Pengujian Hipotesis

\begin{tabular}{|c|c|c|l|c|}
\hline Kode & Hipotesis & $\begin{array}{c}\text { T } \\
\text { statistics }\end{array}$ & P values & Kesimpulan \\
\hline H1 & $\begin{array}{c}\text { Kualitas Layanan } \rightarrow \\
\text { Kepuasan Pelanggan }\end{array}$ & 5,142 & 0.000 & Tidak ditolak \\
\hline H2 & $\begin{array}{c}\text { Kualitas Layanan } \rightarrow \text { Niat } \\
\text { Pembelian }\end{array}$ & 4,212 & 0.000 & Tidak ditolak \\
\hline H3 & $\begin{array}{c}\text { Nilai yang Dipersepsikan } \\
\rightarrow \text { Kepuasan Pelanggan }\end{array}$ & 2,564 & 0,011 & Tidak ditolak \\
\hline H4 & $\begin{array}{c}\text { Nilai yang Dipersepsikan } \\
\rightarrow \text { Niat Pembelian }\end{array}$ & 1,007 & 0.314 & Ditolak \\
\hline H5 & $\begin{array}{c}\text { Kepuasan Pelanggan } \rightarrow \\
\text { Niat Pembelian }\end{array}$ & 2,123 & 0.034 & Tidak \\
\hline H6 & $\begin{array}{c}\text { Kualitas Layanan } \rightarrow \\
\text { Kepuasan Pelanggan } \rightarrow\end{array}$ & 1,916 & 0,056 & Ditolak \\
\hline
\end{tabular}




\begin{tabular}{|c|c|l|l|l|}
\hline & Niat Pembelian & & \\
\hline H7 & $\begin{array}{c}\text { Nilai yang dipersepsikan } \\
\rightarrow \begin{array}{c}\text { Kepuasan Pelanggan } \\
\text { Niat Pembelian }\end{array}\end{array}$ & 1,629 & 0,104 & Ditolak \\
\hline
\end{tabular}

Sumber: Output pengolahan SmartPLS

\section{DISKUSI}

Berdasarkan hasil pengujian hipotesis pertama menjelaskan bahwa kualitas layanan terbukti dapat mempengaruhi secara positif kepuasan pelanggan jasa MRT Jakarta yang berarti H1 tidak ditolak. Hal ini sesuai dengan penelitian Chongsanguan et al (2017) dimana dijelaskan bahwa terdapat kaitan yang signifikan positif antara kualitas layanan terhadap kepuasan pelanggan. Pengujian hipotesis kedua menjelaskan bahwa kualitas layanan terbukti dapat mempengaruhi secara positif niat pembelian pengguna jasa MRT Jakarta yang berarti H2 tidak ditolak. Penelitian ini sesuai dengan penelitian yang dilakukan Mugion et al (2018) dimana dijelaskan bahwa terdapat pengaruh positif antara kualitas layanan terhadap niat pembelian

Hasil pengujian hipotesis yang ketiga menjelaskan bahwa nilai yang dipersepsikan terbukti dapat mempengaruhi secara positif kepuasan pelanggan jasa MRT Jakarta, yang berarti $\mathrm{H} 3$ tidak ditolak. Hasil pengujian hipotesis keempat menjelaskan bahwa nilai yang dipersepsikan terbukti tidak dapat mempengaruhi secara positif niat pembelian pengguna jasa MRT Jakarta, yang berarti H4 ditolak. Hasil pengujian hipotesis kelima menjelaskan bahwa kepuasan pelanggan terbukti dapat mempengaruhi secara positif niat pembelian pengguna jasa MRT Jakarta, yang berarti H5 tidak ditolak. Hasil pengujian hipotesis keenam menjelaskan bahwa bahwa variabel kepuasan pelanggan tidak dapat memedisi pengaruh kualitas layanan terhadap niat pembelian pengguna jasa MRT Jakarta, yang berarti H6 ditolak. Hasil pengujian hipotesis ketujug menjelaskan bahwa variabel kepuasan pelanggan tidak terbukti dapat memedisi pengaruh nilai yang dipersepsikan terhadap niat pembelian pengguna jasa MRT Jakarta yang berarti H7 ditolak.

\section{KESIMPULAN DAN SARAN}

Populasi yang tidak terbatas dalam penelitian ini, sehingga pengambilan sampel dilakukan secara acak dengan menggunakan metode convenience sampling. Variabel-variabel yang digunakan untuk memprediksi niat pembelian pada penelitian ini hanya terbatas pada variabel kualitas pelayanan, nilai yang dipersepsikan dan kepuasan pelanggan. Mahasiswa yang ingin meneliti lebih lanjut diharapkan untuk menambahkan variabel baru lainnya seperti promotion, memperbanyak sampel, dan memperluas wilayah populasi.

\section{DAFTAR PUSTAKA}

Azjen, I. (1991). The Theory Of Planned Behavior. Organizational Behavior and Human Decision Process, 179-211.

Agarwal, S., \& Teas, R. K. (2001). Perceived value: mediating role of perceived risk. Journal of Marketing theory and Practice, 9(4), 1-14.

Aritonang R, Lerbin R. (2007). Riset Pemasaran: Teori dan Praktik. Bogor: Ghalia Indonesia

Bai, B., Law, R., \& Wen, I. (2008). The impact of website quality on customer satisfaction and purchase intentions: Evidence from Chinese online visitors. International journal of hospitality management, 27(3), 391-402. 
Bishop, W. R. Jr., (1984). Competitive intelligence. Progressive grocer, 63(3), 19-20.

Bitner, M.J. and Hubbert, A.R. (1994) 'Encounter satisfaction versus overall service satisfaction versus quality', in Rust, R.T. and Oliver, R.L. (Eds.): Services

Quality: New Directions in Theory and Practice,Sage Publications, Thousand bOaks, CA, pp.72-92,

Bitner MJ. Evaluating service encounters: the effects of physical surrounding on employee responses. J Mark 1990;54:69 - 82.

Chongsanguan, P., Trimetsoontorn, J., \& Fongsuwan, W. (2017). Examining the relationships between service quality, perceived value, customer satisfaction and purchase intentions: a marketing study of Bangkok's metropolitan rapid cohtransit system, Thailand. Journal for Global Business Advancement, 10(1), 3-25..

Dodds, W.B., Monroe, K.B., Grewal, D., 1991. Effects of price, brand, and store information on buyers' product evaluation. Journal of Marketing Research 28 hair(3), 307-319.

Hair, J. F., Ringle, C. M., \& Sarstedt, M. (2011). PLS-SEM: Indeed a silver bullet. Journal of Marketing theory and Practice, 19(2), 139-152.

Henseler, J., Ringle, C.M. and Sinkovics, R.R. (2009), "The use of partial least squares path modeling in international marketing", Advances in International Marketing, Vol. 20, pp. 277-320.

Holbrook, M. B., 1994. The nature of customer value: An axiology of services in the consumption experience. In R. T. Rust \& R. L. Oliver (Eds.), Service quality: New direction on theory and practice: Sage Publication

Hsu, C. L., Chang, K. C., \& Chen, M. C. (2012). The impact of website quality on customer satisfaction and purchase intention: perceived playfulness and perceived flow as mediators. Information Systems and e-Business Management, 10(4), 549-570.

Hu, H., Kandampully, J. and Juwaheer, T.D. (2009) 'Relationships and impacts of service quality, perceived value, customer satisfaction, and image: an empirical study', The Service Industries Journal, Vol. pp.111-125.

Hussain, R., Al Nasser, A., \& Hussain, Y. K. (2015). Service quality and customer satisfaction of a UAE-based airline: An empirical investigation. Journal of Air Transport 175.

Management, 42, $\quad 167-$

Jhandir, S. U. (2012). Customer satisfaction, perceived service quality and mediating role of perceived value. International journal of marketing studies, 4(1).

Johnson, Michael D. and Claes Fornell (1991), “A Framework for Comparing Customer Satisfaction Across Individuals and Product Categories," Journal of Economic Psychology, 12 (2), 267-86.

Juran, J. M. (1988). Juran on planning for quality. Collier Macmillan.

Kuo, Y. F., Wu, C. M., \& Deng, W. J. (2009). The relationships among service perceived value, customer satisfaction, and post-purchase intention

quality, value added services. Computers in Human Behavior, 25(4), 887- 896.

Kotler, P., Keller, K.L., 2009. Marketing management (13th end). New Jersey: $\quad$ Pearson Education Inc, Upper Saddle River: NJ.

Lovelock, C.H., 2000. Service Marketing 4th edition Prentice Hall International, New Jersey. 
MacKinnon, D. P., Fairchild, A. J., \& Fritz, M. S. (2007). Mediation analysis. Annu. Rev. Psychol., 58, 593-614.

Malhotra, NK. (2010). Marketing Research: An Applied Orientation, Sixth Edition.

McDougall, G., \& Levesque, T. (2000). Customer satisfaction with service Putting perceived value into the equation. Journal of Services Marketing, 14(5), 392-410.

Mirza, B., \& Ali, M. (2017). AN ASSESSMENT OF RELATIONSHIP AMONG SERVICE QUALITY, PRICE PERCEPTION AND CUSTOMER SATISFACTION IN THE FORMATION OF CONSUMER'S PURCHASE INTENTION. Kuwait Chapter of the rabian Journal of Business and Management Review, 6(12), 10-21.

Mugion, R. G., Toni, M., Raharjo, H., Di Pietro, L., \& Sebathu, S. P. (2018). Does the service quality of urban public transport enhance sustainable mobility?. Journal of cleaner production, 174, 1566-1587.

Oliver, Richard L. (1999), "Whence Consumer Loyalty?" Journal of Marketing, 63 (Special Issue), 33-44.

Parasuraman, A., Zeithaml, V. A., \& Berry, L. L. (1985). A conceptual model of service quality and its implications for future research. Journal of marketing, 49(4), 41-50

Ponte, E. B., Carvajal-Trujillo, E., \& Escobar-Rodríguez, T. (2015). Influence of trust and perceived value on the intention to purchase travel online: Integrating the effects of assurance on trust antecedents. Tourism Management, 47, 286-302.

Rasoolimanesh, S. M., Dahalan, N., \& Jaafar, M. (2016). Journal of Hospitality and Tourism Management Tourists â€TM perceived value and satisfaction in a community-based homestay in the Lenggong Valley World Heritage Site. Journal of Hospitality and Tourism Management, 26, 72-81.

Ueltschy, L. C., Krampf, R. F., 2001. Cultural sensitivity to satisfaction and Service quality measures. Journal of Marketing Theory and Practice, 14- 31.)

Weinstein, A. (1998) Customer Satisfaction Among Transit Riders: How Customers Rank The Relative Importance Of Various Service Attributes, Transportation Research Record 1735, Transportation Research Board, pp.123-132. Wu.

Wijaya, T. (2009). Analisis Structural Equation Modeling Menggunakan AMOS untuk Penelitian. Yogyakarta \: Universitas Atma Jaya Yogyakarta.

Woodruf, R.B., (1997). Customer value: the next source for competitive advantage. J. Acad, Mark. Sci. 25(2), 139-153.

Zeithaml, V.A. (1988) 'Consumer perceptions of price, quality and value: a means- end model and synthesis of evidence', Journal of Marketing, Vol. 52, pp.2- 22

Zeithaml, V.A., Berry, L.L. and Parasuraman, A. (1996) 'The behavioural consequences of service quality', Journal of Marketing, Vol. 60, No. 2, pp.31-46. 